\author{
Afsheen Aqeel $^{1}(\mathbb{D})$, Zulfiqar Ali Mirani2 ${ }^{(\mathbb{D})}$, Mariyah \\ Yacoob Bawa' ${ }^{1}$, Saima Asif ${ }^{3}$, Rabia Noor ${ }^{3}$, Shumaila \\ Khan $^{3}$ \& Tanveer Abbas ${ }^{1}$ (D)
}

${ }^{1}$ Department of Microbiology, University of Karachi, Karachi-Pakistan.

${ }^{2}$ Food \& Marine Resource Research Centre, PCSIR Labs Complex Karachi, Karachi-Pakistan.

${ }^{3}$ Jinnah University for Women, Karachi-Pakistan.

\section{Original Article \\ Perceptive on bacteriological quality in
foods of animal origin sold in the local
market: Potential threats for the perishable \\ Perceptive on bacteriological quality in
foods of animal origin sold in the local
market: Potential threats for the perishable \\ Perceptive on bacteriological quality in
foods of animal origin sold in the local
market: Potential threats for the perishable food supply chain.}

Doi: 10.29052/IJEHSR.v9.i4.2021.491-498

\section{Corresponding Author Email:}

taabbas@uok.edu.pk

Received 04/01/2021

Accepted 01/05/2021

First Published 23/10/2021

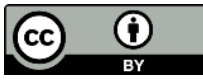

(c) The Author(s). 2021 Open Access This article is distributed under the terms of the Creative Commons Attribution 4.0 International License (http://creativecommons.org/licenses/by/4.0/)

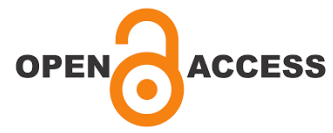

\title{
Abstract
}

Background: Pre and post-harvest spoilage is becoming a severe concern not only in Pakistan but also worldwide. Foodborne illness remains prevalent throughout Pakistan because of the lack of informed risks and safe handling practices of the food preparers and handlers at each food chain point. It causes food spoilage that results in substantial economic losses to both producers (farmers) and consumers. Therefore, this article aimed to review the microbial load of meat, dairy, and seafood products and how the microbial load/population's shelf life and food quality can be affected.

Methodology: During this experimental study, a total 127 samples were collected directly from different industries and included. Total bacterial count (TBC), total coliform count (TCC), fecal coliform count (FCC) and detection of Salmonella were done to check the quality of foods of animal origin collected from the different food industries from 2019 to 2020 and Pakistan standard (P.S.) of food quality was used to compare the results.

Results: Among 127 analyzed samples, 27 (34.29\%) samples were found contaminated with four bacterial parameters, TBC (6.35\%), TCC (19\%), and FCC (8.89\%). At the same time, Salmonella spp were found absent in all of the samples analyzed. Among seven perishable food commodities, the higher percentage of unsatisfactory samples were observed in the chicken meat (1.62\%) and beef meat samples (1.5\%), while fresh milk was highly contaminated $(0.9 \%)$ as compared to the powder milk $(0.42 \%)$, followed by yogurt $(0.26 \%)$. Shrimp (0.26\%) and fish items (0.2\%) showed the least percentage of unsatisfactory samples.

Conclusion: The results suggest that a significant quality difference is observed in the food items sold in the central region of Karachi, further representing a vulnerability to human health in terms of bacteriological hazards. Our findings suggest that safety measures should be taken seriously to stay away from possible uncertainties.

\section{Keywords}

Bacteria, Dairy, Meat and Poultry, Seafood, Public Health. 


\section{Introduction}

Food insecurity is one of the major threatens to humanity due to the large-scale development of the human population. A large proportion of the food gets spoiled, mainly during the food supply chain, especially before receiving by the end-user. The study on the food and Agriculture Organization of the United Nations has suggested that one-third of the food generated for human consumption is wasted or ruined ${ }^{1}$. Thus, food spoilage constitutes a global issue that needs the attention of various researchers in the future to reduce spoilage.

Spoilage can be defined as any objectionable change that turns food unhealthy or unsafe for human utilization. Spoilage of food is the visible growth of microorganisms and the production of acids and other harmful metabolites, resulting in slime, unpleasant taste, odours, and gas formation ${ }^{2,3}$. Even though technological breakthroughs in food science and technology have been amplified, food spoilage remains a worldwide problem ${ }^{4}$. Spoilage of food causes enormous economic losses to manufacturers, retailers, and customers ${ }^{5}$. The spoilage rate can be influenced by factors like indigenous microflora, temperature, $\mathrm{pH}$, water availability or moisture, inappropriate storage, processing procedures, food handlers, and transportation $n^{6,7}$. Apart from food insecurity and cost-effective thrashing, spoiled foods are also a key contributor to food waste. Illness through food remains prevalent all over Pakistan, partly since the food handlers and preparers are not fully aware of hazards and safe handling practices. The most frequent root of food spoilage is microbes because they are ubiquitous. Microbes grow in food in various ways, depending on the nature of food. High moisture content food such as meat, milk, and seafood easily get spoiled by bacteria, unlike low moisture content food ${ }^{8}$.

Nevertheless, the intricacy of food spoilage and the interconnectivity of factors contributing to it make it more intricate to resolve the problem. Therefore, it is suggested that perceptive to different foods' spoilage mechanisms will help develop experiential and evidence-based alleviation strategies. This research paper, therefore, evaluates the bacterial quality of meat, seafood, and milk.

\section{Meat and Poultry}

With time, demand for poultry and meat products has exceeded markedly because of a protein-rich diet. It is one of the most perishable foods, which provides a favourable environment for imitating bacteria since it has high concentrations of nutrients and high water contents ${ }^{8}$. Usually, the shelf-life of meat and meat products depends on the type of microflora and their counts. The species of Salmonella and Clostridium, Staphylococcus aureus, Campylobacter fetus, and Yersinia enterocolitica are the common contaminants of raw meat ${ }^{9}$. Contamination of raw meat is suspected to occur during slicing, wrapping, and handling by workers. Moreover, in smoked, cured, and dried meat, heat-processing is not sufficient, due to which some spore formers and non-spore formers can survive ${ }^{10}$.

\section{Milk and Dairy Products}

Dairy products are bulky and an extremely nutritious medium for microbes ${ }^{11}$. They can be broadly categorized as a perishable commodity, including fresh, skim, fermented and flavoured milk, cream, and cheese, which are relatively stable products such as evaporated and dried milk, butter, and ice creams. Since freshly drawn milk is considered free of microorganisms but can be contaminated through the air, water, soil, straw, feed, and milking utensils ${ }^{12}$. Frequent bacterial contaminants of milk belong to Pseudomonas, Arthrobacter, Alcaligenes, Achromobacter, Aeromonas, Brucella, Enterobacter, Serratia, Campylobacter, Chromobacterium, Flavobacterium, Bacillus, Clostridium, Corynebacterium, Streptococcus, Lactobacillus, Lactococcus, Leuconostoc, and Microbacterium ${ }^{13}$. It has been reported that Staphylococcus aureus and Salmonella species are mostly associated with dried milk, and their presence, even in low numbers, is a serious hazard ${ }^{14}$. Lactic acid bacteria usually proliferate in raw milk and produce offflavours at room temperature, mainly by producing lactic acid $^{15}$. In pasteurized milk, heat-tolerant 
species of Alcaligenes, Microbacterium, Bacillus, and Clostridium survive and cause spoilage ${ }^{16}$.

\section{Fish, Prawn, Shrimps and Other Seafood}

Fish and other seafood consist of high protein, lowfat nutrients, and omega 3-fatty acids. Studies suggest that Aquaculture products are highly perishable, and therefore, spoilage transpires quickly and limits their shelf lives ${ }^{17}$. Another study stated that cleaning and disinfection are not enough to detach pathogenic bacteria from the surfaces of perishable food ${ }^{18}$. Moreover, it is suggested that the isolated bacteria, including (Aeromonas, Alcaligenes, Bacillus, Enterobacter, Enterococcus, Escherichia coli, Listeria, Pseudomonas, Shewanella) are from fresh and spoiled fish and other kinds of seafood ${ }^{19}$. Members of Vibrionaceae are the common spoilage causing bacteria in unpreserved fish. Whereas species of Pseudomonas and Shewanella deteriorate frozen fish $^{20}$. In particular, most Vibrio species have been linked with foodborne infection resulting from consuming uncooked and partially cooked fishery products $^{21}$.

\section{Methodology}

This experimental study was carried out in Karachi, Pakistan, from February 2018 to January 2019. A total of 127 samples were collected directly from different industries and divided into categories including, 27 chicken meat samples, 25 beef meat samples, 20 fish samples, 13 shrimp samples, 15 fresh milk samples, 14 powder milk samples, and 13 yogurt samples. Samples were taken aseptically in polyethylene bags with labels and immediately brought to the laboratory for quantitative and qualitative microbiological analysis.

Frozen samples were stored at $-20^{\circ} \mathrm{C}$ for less than 24 hours, and perishable food samples were stored at $0-4{ }^{\circ} \mathrm{C}$, while none perishable were stored at room temperature for less than 24 hours. Microbiological parameters included total bacterial count (TBC), total coliform count (TCC), fecal coliform count (FCC), and Salmonella spp. These parameters were followed as mentioned in the Bacteriological Analytical Manual (BAM).
50 grams of each sample was placed in the blender jar along with $450 \mathrm{ml}$ of sterile Butterfield's phosphate buffer and was mixed well for at least 2 minutes (with specifically 1:10 dilution). Then serial dilutions were made by transferring $10 \mathrm{~mL}$ of successive dilution to a universal bottle containing $90 \mathrm{ml}$ of sterile Butterfield's phosphate buffer. These suspensions were seeded in different culture media with specific standard methods described by BAM.

The total bacterial count was determined using the pour plate method. $1 \mathrm{~mL}$ of the sample from the three dilutions (1:10, 1:100, and 1:1000) was transferred to each duplicate Petri dish. Then Plate count agar (PCA) (Oxoid) was poured into each Petri dish and incubated at $35^{\circ} \mathrm{C}$ for 48 hours \pm 2 hours. Colonies were counted by colony counter from duplicate plates containing 25-250 colonies, and the result was expressed as $\mathrm{cfu} / \mathrm{mL}$. The blank plate of PCA was used as a control.

TCC and FCC were determined by the Most Probable Number (MPN) method. We Inoculate 1 $\mathrm{mL}$ of each dilution (1:10, 1:100, and 1:1000) into three sets of $10 \mathrm{~mL}$ Lauryl tryptone broth (LTB) (Oxoid). These LTB tubes and inverted Durham tubes were incubated at $35 \pm 0.5^{\circ} \mathrm{C}$ for 24 and 48 \pm 2 hours after inoculation. Tubes were examined for gas production at the end of 24/48 hours incubation. Gas production was measured by gas displacement in the inverted vial and effervescence production when the tube was gently shaken.

For the confirmation of coliform, positive tubes with gas and turbidity were subcultured into Brilliant Green Lactose bile broth (BGB) and incubated at $35 \pm 0.5^{\circ} \mathrm{C}$ for gas production $48 \pm 2$ hrs. MPN was calculated on the confirmation of gassing LST tubes for 3 consecutive dilutions. For the confirmation of fecal coliform, 10 mLof E.C. broth with inverted Durham tubes was inoculated by a loopful of each suspension incubated at 44.5 $\pm 0.2^{\circ} \mathrm{C}$ for $24 \pm 2$ hours and was examined for gas production. Total coliform and fecal coliform were calculated from the MPN index. Lauryl Tryptone broth (LTB) (Oxoid) acts as a blank control. The test 
tubes with E.coli were used as positive control while S. aureus was considered negative.

Pre-enrichment was transferred $25 \mathrm{~g} / \mathrm{mL}$ of homogenized samples aseptically in $225 \mathrm{~mL}$ of sterile universal pre-enrichment broth containing Lactose broth (Oxoid) and was then incubated for $24 \pm 2$ hours at $35^{\circ} \mathrm{C}$. Afterward, pre-enriched culture was then typically subcultured into two different selective enrichment media, such as Rappaport-Vassiliadis medium (RVS)(Oxoid) and Tetrathionate Broth (TTB) (Oxoid). It then was incubated for $24 \pm 2$ hours at $43 \pm 0.2^{\circ} \mathrm{C}$. Further isolation was done by transferring positive RVS and TTB on Bismuth Sulfite (B.S.) Agar, Xylose Lysine Desoxycholate (XLD) Agar, and Hektoen Enteric (HE) Agar. Plates were incubated for $24 \pm 2$ hours at $35^{\circ} \mathrm{C}$ then examined for typical colonies of Salmonella spp. S. Typhi was used as a positive control, while E.coli was used as a negative control. Identification was further made by performing the urease test, oxidase test and Triple sugar iron (TSI).

All experimental data analyses were done in triplicates, and interpretations were presented as Mean \pm SD. Observed data were subjected to analysis of variance and t-test using SPSS version 20.0 .

\section{Results}

Total 127 samples were collected from the local market that comprised of chicken meat, beef meat, fish, shrimp, fresh milk, powder milk, and yogurt
(Table 1). Bacterial profiles were estimated by using 4 microbiological parameters that include the TBC, TCC, FCC and detection of Salmonella spp. Results revealed that out of 127 samples analyzed, overall, 27 (34.29\%) samples were found contaminated with the parameters mentioned above, TBC (6.35\%), TCC (19\%), and FCC (8.89\%). Whereas Salmonella spp were found absent in all of the samples analyzed (Table 1).

Obtained values were compared with Pakistan standards (P.S.) (Table 2) to measure food quality and shown in table 1.

As the table 1 described, out of 127 samples 69 were estimated on satisfactory limits in terms of total bacterial count (TBC). In which beef meat (raw) showed high number of satisfactory samples with a mean of $4.19 \pm 4.51 \log 10 \mathrm{cfu} / \mathrm{g}$ or $\mathrm{mL}$. While 53 samples were found on the borderline limits in which highest number of samples were observed in chicken meat (raw) (Mean $4.19 \pm 4.51 \mathrm{cfu} / \mathrm{g}$ or $\mathrm{mL}$ ). Whereas 5 samples have been fallen into the unsatisfactory category, in which the prominent commodity was milk (fresh) with a mean of $4.88 \pm$ $3.53 \mathrm{cfu} / \mathrm{g}$ or $\mathrm{mL}$. Similarly in TCC and FCC parameters, 69 and 78 samples out of 127 were in the satisfactory category where highest number has been observed in chicken meat for TCC with a mean value of $3.19 \pm 4.52 \log 10 \mathrm{cfu} / \mathrm{g}$ or $\mathrm{mL}$ and Beef meat $(2.47 \pm 2.08 \log 10 \mathrm{cfu} / \mathrm{g}$ or $\mathrm{mL})$ for FCC. It was found that Salmonella was absent in all of the samples analyzed.

Table 1: Bacterial profile of perishable food items reported after comparing with Pakistan standard.

\begin{tabular}{|c|c|c|c|c|c|c|c|c|c|c|c|c|c|}
\hline \multirow[t]{2}{*}{ Food samples } & \multirow[t]{2}{*}{ n } & \multicolumn{3}{|c|}{ TBC } & \multicolumn{3}{|c|}{ TCC } & \multicolumn{3}{|c|}{ FCC } & \multicolumn{3}{|c|}{ Salmonella } \\
\hline & & $\mathbf{s}$ & b & $\mathbf{u}$ & $\mathbf{s}$ & b & $\mathbf{u}$ & $\mathbf{s}$ & b & $\mathbf{u}$ & $\mathbf{s}$ & b & $\mathbf{u}$ \\
\hline Chicken meat ( Raw) & 27 & 11 & 15 & 1 & 14 & 10 & 3 & 12 & 13 & 2 & 0 & 0 & 0 \\
\hline Beef meat ( Raw) & 25 & 15 & 9 & 1 & 11 & 10 & 4 & 18 & 6 & 1 & 0 & 0 & 0 \\
\hline Fish (raw and frozen) & 20 & 11 & 9 & 0 & 11 & 8 & 1 & 10 & 9 & 1 & 0 & 0 & 0 \\
\hline Shrimp (raw and frozen) & 13 & 8 & 5 & 0 & 7 & 4 & 2 & 7 & 6 & 0 & 0 & 0 & 0 \\
\hline Milk (Fresh) & 15 & 5 & 8 & 2 & 7 & 6 & 2 & 9 & 4 & 2 & 0 & 0 & 0 \\
\hline Milk (Powder) & 14 & 9 & 4 & 1 & 11 & 2 & 1 & 11 & 2 & 1 & 0 & 0 & 0 \\
\hline Yogurt & 13 & 10 & 3 & 0 & 8 & 3 & 2 & 11 & 2 & 0 & 0 & 0 & 0 \\
\hline Total & 127 & 69 & 53 & 5 & 69 & 43 & 15 & 78 & 42 & 7 & 0 & 0 & 0 \\
\hline
\end{tabular}


TBC-Total bacterial count, TCC-Total coliform count, FCC-Fecal coliform count. S-satisfactory limits, b-borderline limits, u-unsatisfactory limits.

Table 2: Standard limits for perishable food commodities as per Pakistan standards (P.S.)

\begin{tabular}{|c|c|c|c|c|c|c|c|}
\hline \multirow{3}{*}{$\begin{array}{l}\text { Food items } \\
\text { description }\end{array}$} & \multicolumn{6}{|c|}{ Pakistan Standard limits (cfu/g or $\mathbf{m L}$ ) } & \multirow{3}{*}{$\begin{array}{l}\text { Pakistan Standard } \\
\text { Ref \# }\end{array}$} \\
\hline & \multicolumn{3}{|c|}{ TBC } & \multicolumn{3}{|c|}{ TCC } & \\
\hline & $\mathbf{S}$ & b & $\mathbf{u}$ & s & b & $\mathbf{u}$ & \\
\hline $\begin{array}{l}\text { Milk \& dairy } \\
\text { products }\end{array}$ & $10^{3}$ & $\begin{array}{l}>103- \\
<104\end{array}$ & $>104$ & 102 & $\begin{array}{l}>102- \\
<103\end{array}$ & 103 & $\begin{array}{c}2835-1990, \quad 363-1991,2832-1- \\
1990, \quad 2027-1988\end{array}$ \\
\hline Chicken meat & $5 \times 10^{3}$ & $\begin{array}{l}>103- \\
<107\end{array}$ & 107 & 10 & $\begin{array}{l}>10- \\
<102\end{array}$ & 102 & $4726-2001$ \\
\hline Meat & $10^{4}$ & $\begin{array}{l}>104- \\
<105\end{array}$ & 105 & 10 & $\begin{array}{l}>10- \\
<102\end{array}$ & 102 & $\begin{array}{c}2861-1990,2826-1990,2827- \\
1990,2988-1991\end{array}$ \\
\hline $\begin{array}{l}\text { Fish and other } \\
\text { Seafood }\end{array}$ & $5 \times 10^{5}$ & $\begin{array}{l}<105- \\
<107\end{array}$ & 107 & 102 & $\begin{array}{l}>102- \\
<103\end{array}$ & $>103$ & 2834 \\
\hline
\end{tabular}

Table 3: Estimation of Mean log10cfu/g or $\mathrm{mL}$ tested food commodities.

\begin{tabular}{lcccc}
\hline \multirow{2}{*}{ Food samples } & \multicolumn{4}{c}{$\log \mathbf{1 0} \mathbf{c f u} / \mathbf{g}(\mathbf{m L})$} \\
\cline { 2 - 5 } & TBC & TCC & FCC & Salmonella \\
\hline Chicken meat ( Raw) & $4.19 \pm 4.51$ & $3.19 \pm 4.52$ & $1.57 \pm 2.22$ & N.D. \\
\hline Beef meat ( Raw) & $4.19 \pm 4.51$ & $3.07 \pm 4.34$ & $2.47 \pm 2.081$ & N.D. \\
\hline Fish (raw and frozen) & $4.49 \pm 4.94$ & $1.66 \pm 2.34$ & $2.27 \pm 1.48$ & N.D. \\
\hline Shrimp (raw and frozen) & $2.02 \pm 1.44$ & $2.94 \pm 4.16$ & $2.45 \pm 3.47$ & N.D. \\
\hline Milk (Fresh) & $4.88 \pm 3.53$ & $2.45 \pm 3.47$ & $3.18 \pm 4.49$ & N.D. \\
\hline Milk (Powder) & $1.92 \pm 1.30$ & $1.60 \pm 2.26$ & $3.07 \pm 4.34$ & N.D. \\
\hline Yogurt & $4.02 \pm 2.85$ & $2.30 \pm 3.25$ & $3.16 \pm 4.47$ & N.D. \\
\hline
\end{tabular}

TBC-Total bacterial count, TCC-Total coliform count, FCC-Fecal coliform count, cfu/g (mL)-colony forming unit in $1 \mathrm{gram}$ or milliliter, SD-standard deviation; N.D.-Not detected

\section{Discussion}

Food spoilage is not the only cause of food loss, but it is also considered a major source of foodborne illness. Food quality and safety are great apprehensions to humanity. Moreover, it can be well thought-out as a multifaceted feature that concludes food's value or satisfactoriness to a user/consumer. Our results suggest that out of 127 samples, overall, 27 (34.29\%) samples were found contaminated. These results indicate alarming and poor food hygienic conditions prevalent in the local market. Comi in 2017, carried out similar work and reported higher contamination levels in food samples ${ }^{21}$.

Moreover, the European Food Safety Authority also reported a higher contamination level in food 
items compared to our results ${ }^{23}$. Among seven perishable food commodities in our study, a higher percentage of unsatisfactory samples was observed in the chicken meat (1.62\%) and beef meat samples (1.5\%) (Table 1). Our findings are similar to the results of Jan et al., who recorded heavily polluted samples of meat ${ }^{24,25}$.

When talking about milk, it is nutritional and a portion of ideal food for all groups of individuals ${ }^{26}$. In our study, the results suggest that fresh milk was highly contaminated (0.9\%) as compared to powder milk $(0.42 \%)$, followed by yogurt $(0.26 \%)$. Our findings are in line with the previous report, which estimated different contamination levels in milk samples ${ }^{27}$. A recent study also claimed high contamination of milk samples (60\%) with Bacillus cereus, with a bacterial count above the specified limit ( $>10^{5} \mathrm{CFU} / \mathrm{mL}$ ) for human use ${ }^{13}$. Seafood serves as a host to the abundant bacteria present in seawater. It is suggested that off-odour or offflavour of seafood occurs because of volatile organic compounds (VOCs). In the present study, Shrimp (0.26\%) and fish items (0.2\%) showed the least unsatisfactory samples suggesting the least food spoilage. Contrary to our results, studies show an elevated level of contamination in fishes ${ }^{23-28}$. In contrast, another study has also reported spoilage in freshwater fish ${ }^{29}$, suggesting that there is always a chance of higher bacterial counts in seafood due to deprived management at some point in the process of gutting and scaling ${ }^{30}$.

Unfortunately, pathogenic bacteria present in food are not easily detected. It would be very hard, costeffective, and time-consuming to monitor them. So, it is required to choose an easy protocol "indicator organism," whose existence indicates pathogenic organisms may be present in that sample. Total coliform bacteria are common in the intestines of animals and the environment, and generally, they are not harmful. But the ratio of Fecal coliform and Escherichia coli are found in greater quantities than total coliform in animal fecal matter. If F.C. or E. coli is detected along with T.C. in foods, there is always strong evidence that samples are fecally contaminated; consequently, pathogens have greater potential. In the present study, the most frequent contamination was observed in TCC (19\%) among the four investigated parameters, followed by FCC (8.89\%) and TBC (6.35\%). These levels indicate spoilage microorganisms reflect the poor microbiological quality and suggest poor adherence to good manufacturing process ${ }^{31}$. Certain causes may be involved in coliform contamination like transport, handling, and water used for cleaning or icing purpose $^{32}$. Hertanto et al., 2018 reported a lesser fecal coliform count in tested food samples compared to our result ${ }^{33}$. Furthermore, coliform in food surfaces does not essentially mark fecal contaminations, but it can help detect poor hygiene during preparation and processing ${ }^{34}$.

Globally, Salmonellosis is considered the main foodborne outbreak and a principal cause of death. In this study, the prevalence of Salmonella in food items was not found. These results align with the previous report; world health organization (WHO) reported a lower frequency of Salmonella in different food samples in developed countries like New Zealand ${ }^{35}$. To discontinue the ruining of foodstuffs, strict checks of quality at a marketplace should be in practice, and butchers, preparers and handlers must get awareness about hygiene, sanitation, sterilization methods, and modern techniques.

\section{Conclusion}

The current study suggests that foods sold in the central region of Karachi represent a vulnerability to human health in terms of bacteriological hazards. The presence of pathogenic strains in foods could serve as a decisive vehicle for transmitting resistant organisms to consumers. In addition, the lack of hygiene was confirmed by the existence of coliform and is a clear indication of post-handling defilement or poor cooking and unsanitary conditions. Overall possible sources of high microbial load observed in samples obtained might be a shortage of freezing facilities, inappropriate processing, predominantly in fresh or raw produces, applying of polluted water for cleaning or irrigation of the fruits or growing them in contaminated soil could be serious ground 
reasons of potential pathogens which have been involved in causing foodborne sickness.

\section{Conflicts of Interest}

The authors have declared that no competing interests exist.

\section{Acknowledgement}

We are thankful to the staff of Microbiology, PCSIR Laboratories Complex Karachi for supporting this study.

\section{Funding}

The author(s) received no specific funding for this work.

\section{References}

1. Gallagher MS, Mahajan PV. The stability and shelf life of fruit and vegetables. InFood and Beverage Stability and Shelf Life 2011 (pp. 641-656). Woodhead Publishing.

2. Blackburn SM, Garner R, Hoffmann C, Khang AM, McKinley KS, Bentzur R, Diwan A, Feinberg D, Frampton D, Guyer SZ, Hirzel M. The DaCapo benchmarks: Java benchmarking development and analysis. In Proceedings of the 21st annual ACM SIGPLAN conference on Object-oriented programming systems, languages, and applications 2006 (pp. 169-190).

3. Lianou A, Panagou EZ, Nychas GJ. Microbiological spoilage of foods and beverages. InThe stability and shelf life of food 2016 (pp. 3-42). Woodhead Publ.

4. Petruzzi L, Capozzi V, Berbegal C, Corbo MR, Bevilacqua A, Spano G, Sinigaglia M. Microbial resources and enological significance: Opportunities and benefits. Front. microbiol. 2017;8:995.

5. Snyder $A B$, Worobo RW. The incidence and impact of microbial spoilage in the production of fruit and vegetable juices as reported by juice manufacturers. Food Control. 2018 ;85:144-150.

6. Ioannidis JP. The challenge of reforming nutritional epidemiologic research. JAMA. 2018 ;320(10):969970.

7. Mageswari A, Subramanian $P$, Srinivasan $R$, Karthikeyan S, Gothandam KM. Astaxanthin from psychrotrophic Sphingomonas faeni exhibits antagonism against food-spoilage bacteria at low temperatures. Microbio. research. 2015;179:38-44.
8. Húngaro HM, Caturla MY, Horita CN, Furtado MM, Sant'Ana AS. Blown pack spoilage in vacuumpackaged meat: a review on clostridia as causative agents, sources, detection methods, contributing factors and mitigation strategies. Trends in food sci Tech. $2016 ; 52: 123-138$.

9. Bhaisare DB, Thyagarajan D, Churchil RR, Punniamurthy N. Bacterial pathogens in chicken meat. Int J Life Sci Res. 2014;2(3):1-7.

10. da Cunha-Neto A, Carvalho LA, Carvalho RC, dos Prazeres Rodrigues D, Mano SB, de Souza Figueiredo EE, Conte-Junior CA. Salmonella isolated from chicken carcasses from a slaughterhouse in the state of Mato Grosso, Brazil: antibiotic resistance profile, serotyping, and characterization by repetitive sequence-based PCR system. Poult sci. 2018;97(4):1373-1381.

11. Fusco V, Chieffi D, Fanelli F, Logrieco AF, Cho GS, Kabisch J, Böhnlein C, Franz CM. Microbial quality and safety of milk and milk products in the 21st century. Comprehensive Reviews in Food Science and Food Safety. $2020 ; 19(4): 2013-2049$.

12. Ledenbach LH, Marshall RT. Microbiological spoilage of dairy products. InCompendium of the microbiological spoilage of foods and beverages 2009 (pp. 41-67). Springer, New York, NY.

13. Msalya G. Contamination levels and identification of bacteria in milk sampled from three regions of Tanzania: evidence from literature and laboratory analyses. Vet. Med. Int. 2017.

14. Oliver JD. Wound infections caused by Vibrio vulnificus and other marine bacteria. Epidemiol. Infect. 2005;133(3):383-391.

15. Quigley L, O'Sullivan O, Stanton C, Beresford TP, Ross RP, Fitzgerald GF, Cotter PD. The complex microbiota of raw milk. FEMS Microbiol. Rev.. 2013;37(5):664-698.

16. Ranieri ML, Ivy RA, Mitchell WR, Call E, Masiello SN, Wiedmann M, Boor KJ. Real-time PCR detection of Paenibacillus spp. in raw milk to predict shelf life performance of pasteurized fluid milk products. Appl. Environ. Microbiol. $2012 ; 78(16): 5855-5863$.

17. Sadeq JN, Mohamed BJ, Hussain MH. Isolation and identification of some bacteria from imported meat (beef burger) by using vitek2 technique. QJVMS. 2018;17(2):117-124.

18. Rawat S. Food Spoilage: Microorganisms and their prevention Asian J. Plant Sci. 2015;5(4):47-56.

19. Pal M, Mulu S, Tekle M, Pintoo SV, Prajapati J. Bacterial contamination of dairy products. Beverage and food world. 2016;43(9):40-43.

20. Wang F, Fu L, Bao X, Wang Y. The spoilage microorganisms in seafood with the existed quorum 
sensing phenomenon. J Food Microbiol. 2017;1(1):14-19.

21. Comi G. Spoilage of meat and fish. InThe microbiological quality of food 2017 (pp. 179-210). Woodhead Publ.

22. PSQCA. Pakistan Standard \& Quality Control Authority. Available at: https://updated.psqca.com.pk

23. European Food Safety Authority, European Centre for Disease Prevention and Control. Multi-country outbreak of Salmonella Agona infections linked to infant formula. 2018.

24. Jan A, Hasan Z, Shah H, Ullah R, Ahmad I, Younas M. An investigation of the bacterial flora causing spoilage of fishes at board fish market, Peshawar, Pakistan. Pakistan J. Zool. 2014;46(5):1371-1375.

25. Borch E, Kant-Muermans ML, Blixt Y. Bacterial spoilage of meat and cured meat products. Int. J. Food Microbiol. 1996; 33(1):103-120.

26. Balthazar CF, Silva HL, Esmerino EA, Rocha RS, Moraes J, Carmo MA, Azevedo L, Camps I, Abud YK, Sant'Anna C, Franco RM. The addition of inulin and Lactobacillus casei 01 in sheep milk ice cream. Food chem. 2018;246:464-472.

27. Odeyemi OA, Burke CM, Bolch CJ, Stanley R. Evaluation of spoilage potential and volatile metabolites production by Shewanella baltica isolated from modified atmosphere packaged live mussels. Int. Food Res. J. 2018 ;103:415-425.
28. Jalal KC, Akbar J, Nurul L, Faizul HN, Isma Y, Irwandi J, Mahbuba B. Comparative study on spoilage and pathogenic bacteria in selected commercial marine and freshwater fishes. Int. Food Res. J. 2017;24(Suppl.):S298-S304.

29. Boziaris IS, Parlapani FF. Specific spoilage organisms (SSOs) in fish. InThe microbiological quality of food 2017 (pp. 61-98). Woodhead Publ.

30. Corlett DA. HACCP user's manual. Springer Science \& Business Media; 1998.

31. Skipnes D. Heat processing of fish. Seafood Processing: Technology, Quality and Safety; Wiley: Hoboken, NJ, USA. 2014 :61-81.

32. Novoslavskij A, Terentjeva M, Eizenberga I, Valcina O, Bartkevičs V, Bērziňš A. Major foodborne pathogens in fish and fish products: a review. Ann. Microbiol. 2016; 66(1):1-5.

33. Hertanto BS, Nurmalasari CD, Nuhriawangsa AM, Cahyadi M, Kartikasari LR. The physical and microbiological quality of chicken meat in the different type of enterprise poultry slaughterhouse: a case study in Karanganyar District. InIOP Conference Series: Earth and Environmental Science 2018 (Vol. 102, No. 1, p. 012051). IOP Publishing.

34. Sivaraman G.K., Siva V. Microbiological spoilage of dried fishes. Available at SSRN 2709070. 2015.

35. Hammond JS, Keeney RL, Raiffa H. Smart choices: A practical guide to making better decisions. Harvard Business Review Press; 2015. 